\title{
Nitrogen-induced Changes in the Growth and Metabolism of Cultured Potato Tubers
}

\author{
Junne-Jih Chen and Yu-Ju Liao \\ Technique Department, Taiwan Seed Improvement and Propagation Station, Hsinshe, Taichung, Taiwan \\ 426, Republic of China
}

Additional index words. cell number, cell size, in vitro tuberization, Solanum tuberosum, tuber development

\begin{abstract}
The effect of $\mathrm{N}$ source on 'Kennebec' potato (Solanum tuberosum L.) tuberization was investigated using singlenode segments originated from in vitro virus-free plantlets and inoculated on media with two nitrate : ammonia ratios (low, 2:1; high, 5:1). Cell count and size and sugar-use characteristics were measured at intervals of tuber development. Tubers grown on high nitrate-ammonia medium exhibited higher rates of sucrose use and higher dry-matter accumulation than tubers grown on low nitrate-ammonia medium. The median value of tuber fresh weight increased from 0.66 to $1.23 \mathrm{~g}$ as a result of increasing nitrate-ammonia. Significant differences in cell size and growth rate were observed between the two $\mathrm{N}$ treatments. There was also a high correlation between tuber cell size and dry matter $(r=0.82, P \leq 0.05)$. These data demonstrate the importance of the nitrate : ammonium ratio in determining $C$ use, tuber cell size, and tuber weight. Chemical names used: $\alpha$ - naphtylacetic acid (NAA); 6-benzylaminopurine (BA).
\end{abstract}

In vitro potato tuberization has been studied extensively (Garner and Blake, 1989; Wang and Hu, 1982), with major efforts focused on tuber initiation factors and shortening the time required for tuber initiation (Koda and Okazawa, 1988; Vreugdenhil and Struik, 1989). In particular, emphasis has been placed on culturing excised stolons in vessels for the mass production of tubers rather than for tuber quality (Wang and $\mathrm{Hu}, 1982$ ).

Seed tuber size is one of the main yield determinants (Peterson et al., 1985). Planting larger in vitro-produced seed tubers, while maintaining a constant seeding rate, would give higher yields and larger tubers (Wiersema et al., 1987). Tuber size is a function of the number and size of cells (Duncan and Ewing, 1984; Vreugdenhil and Struik, 1989). Koda and Okazawa (1983) reported that early tuber growth was caused primarily by cell division followed by radial cell expansion. However, Reeve et al. (1973) suggested that cell enlargement was the main factor affecting tuber volume. Sung and Chen (1990) further reported that cell enlargement was affected strongly by assimilate supply from maternal tissue.

Leaflet photosynthesis in vitro tends to be considerably lower than in-soil-grown plants because of physiological stress, abnormal plant morphogenesis, or both (Ziv, 1986). Nutrients required to sustain tuber growth are largely drawn from the culture medium. Therefore, any factor influencing the uptake of nutrients, especially C, eventually would affect tuber growth (Mezzetti et al., 1991; Stafford and Fowler, 1983). Nitrate and ammonia are the two common $\mathrm{N}$ sources used in tissue culture. The form of $\mathrm{N}$ supplied to plants may influence their uptake of other nutrients (Schmitz and Lorz, 1990). Davis et al. (1989) reported that potato preferentially took up nitrate over ammonia. A low level of ammonia supply in combination with nitrate is beneficial to tuber growth, whereas a high level of ammonia supply is detrimental (Gamer and Blake, 1989).

We found that decreasing $\mathrm{N}$ concentration from 60 to $30 \mathrm{~mm}$ would result in increased sucrose use in developing potato tubers (unpublished data). This study was designed to examine whether changing the nitrate : ammonia ratio in the culture medium could influence cell enlargement and subsequent tuber development.

Received for publication 23 Oct. 1992. Accepted for publication 15 Mar. 1993. This work was supported by the National Science Council, Republic of China, under grant NSC 800409B05301. The cost of publishing this paper was defrayed in part by the payment of page charges. Under postal regulations, this paper therefore must be hereby marked advertisement solely to indicate this fact.

\section{Materials and Methods}

Single-node segments excised from in vitro-cultured 'Kennebec' potato plants were inoculated onto tuber-induction medium composed of Murashige and Skoog (MS) basic salts (Murashige and Skoog, 1962) (except N source) supplemented with 8\% sucrose, $2.69 \mu \mathrm{M}$ NAA, and $17.8 \mu \mathrm{M}$ BA. The N content of two treatments differed in the nitrate : ammonia ratio but had the same total $\mathrm{N}$ as that of MS medium. The high nitrate-ammonia solution contained $50 \mathrm{~mm}$ nitrate and $10 \mathrm{~mm}$ ammonia and the low nitrate-ammonia solution contained $40 \mathrm{~mm}$ nitrate and $20 \mathrm{~mm}$ ammonia. Before the medium was autoclaved, its $\mathrm{pH}$ was adjusted to 5.7. Each flask $(100 \mathrm{ml})$ contained $10 \mathrm{ml}$ of liquid medium and $2 \mathrm{~g}$ of perlite. One single-node segment was inoculated per flask on the top of perlite. The flask was maintained at $20 \mathrm{C}$ in darkness.

Twenty tubers were sampled at 14-day intervals in each treatment. Samples were dried at $78 \mathrm{C}$ for 2 days and dry weights were determined. The $\mathrm{pH}$ of the medium was measured, and depletion of sucrose, glucose, fructose, nitrate, and ammonia from the medium was determined by enzymatic assays using kits from Boering Mannheim Biochemical Co. (1989).

For determining tuber cell count and size, 20 tubers sampled at 14-day intervals were fixed in glutaraldehyde, followed by a graded series of alcohol and tertbutyl alcohol dehydration and embedded in paraffin. Samples were cut into $10-\mu \mathrm{m}$ cross-sections, stained with safranin and fast green, and examined under a microscope. Cell diameter was measured using a micrometer. The number of cells per maximum cross-sectional area per tuber was determined using the line-transect technique (Lin and Chang, 1981). A 300- $\mu \mathrm{m}$ straight line was laid in the observation field and the number of cells that was intercepted by the line was converted to total number per maximum cross-sectional area. Fifty sectioned samples per tuber were measured and the means are reported.

\section{Results and Discussion}

Cell count per cross-sectional area per tuber increased rapidly during the first 42 days and reached a plateau around 56 days after culture initiation (Fig. 1a). Although the rate of cell division for tubers grown on high nitrate-ammonia medium was $40 \%$ higher than those grown on low nitrate-ammonia medium, only $20 \%$ to $25 \%$ of the difference in maximum cell count was due to treatment. 
Cell size was similar for tubers in the two $\mathrm{N}$ treatments during the rapid cell division phase (Fig. 1b). A significant difference in cell enlargement between treatments occurred after 42 days of culture. The maximum size of tuber cell ranged from $28 \mu \mathrm{m}$ for tubers grown on low nitrate-ammonia medium to $42 \mu \mathrm{m}$ for tubers grown on high nitrate-ammonia medium. Duncan and Ewing (1984) and Koda and Okazawa (1983) suggested that cell enlargement in potato precedes active cell division. However, our data showed little change in cell size until the tuber attained $75 \%$ to $85 \%$ of its maximum cell count ( $\approx 28$ to 35 days after culture). This observa-

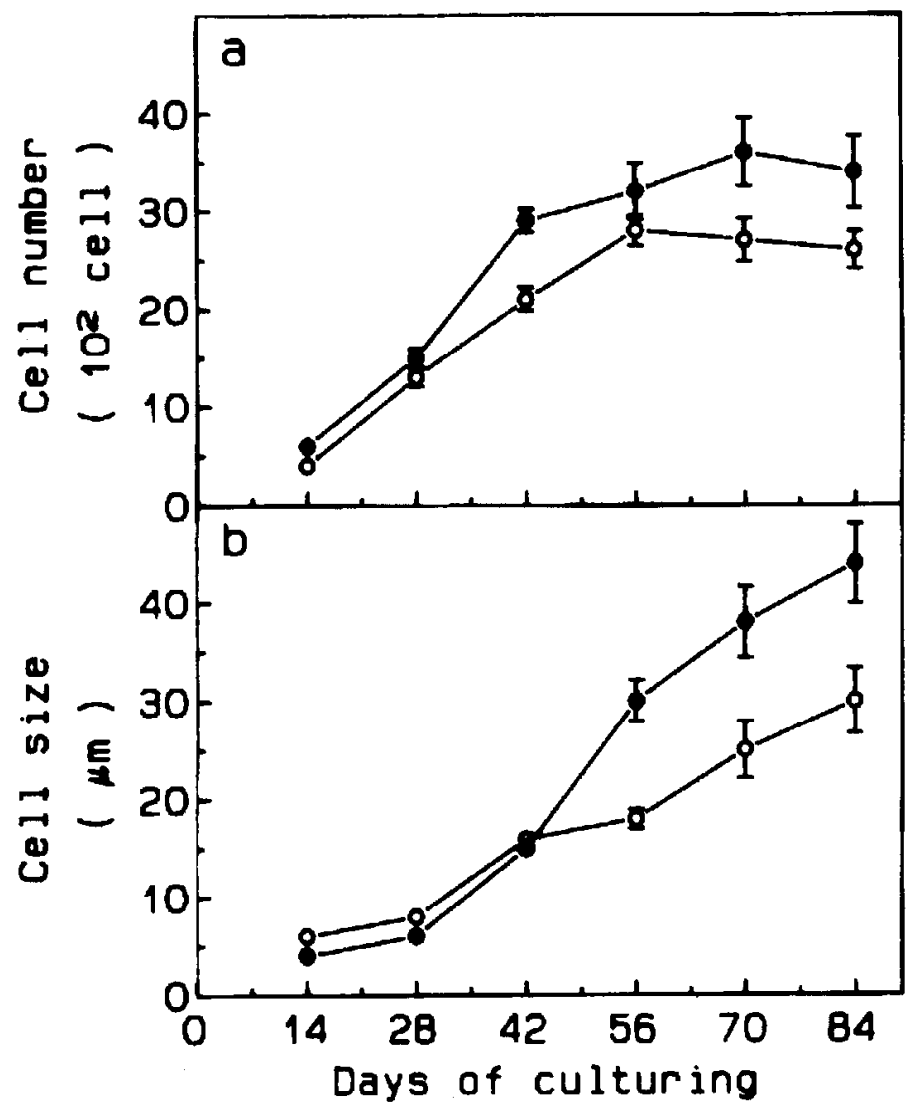

Fig. 1. Changes in cell count (a) and size (b) of potato tubers grown on medium containing high (5:1) ( ) or low $(2: 1)(\mathrm{O})$ nitrate-ammonia during potato tuber development. Vertical bars denote \pm sE.

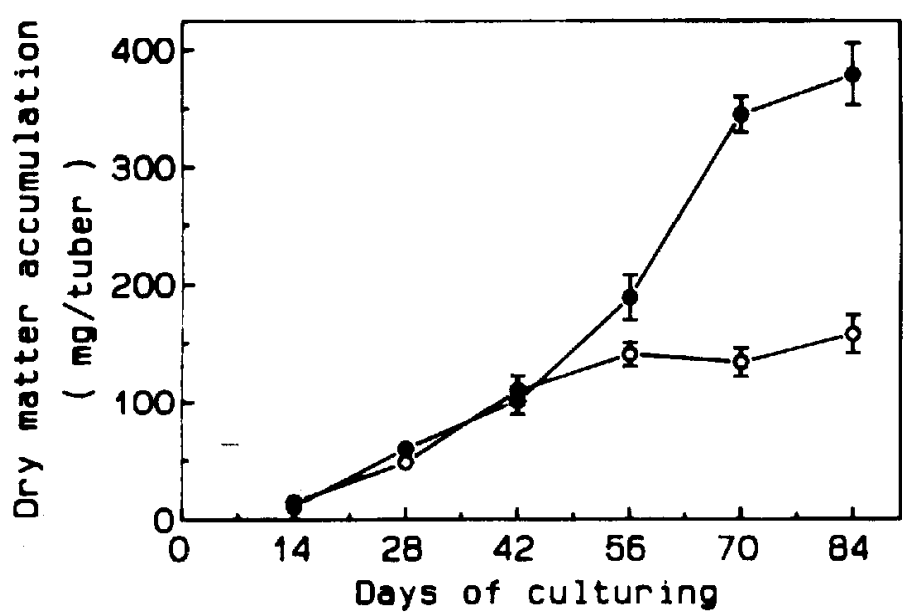

Fig. 2. Time-course of dry-matter accumulation in potato tuber grown on medium containing high $(5: 1)(\mathbf{O})$ or low $(O)(2: 1)$ nitrate-ammonia during potato tuber development. Vertical bars denote $\pm \mathrm{SE}$. tion supports the findings of Reeve et al. ( 1973) on potato and Sung and Chen (1990) on peanut (Arachis hypogaea L.).

For tubers grown on low nitrate-ammonia medium, $\approx 75 \%$ of the final dry weight was accumulated during the first 42 days of culture and $26 \%$ of the final dry matter was accumulated during the same period for tubers grown on high nitrate-ammonia medium (Fig. 2). The tuber growth rate, estimated by fitting a linear regression to tuber dry matter in linear accumulation phase, ranged from 2.3 to $11.7 \mathrm{mg}$ per tuber per day. The change in tuber drymatter accumulation seemed to be closely correlated with cytological change in tuber cell size. The close relationship between tuber cell size and dry matter $(r=0.82, P \leq 0.05)$ across the two $\mathrm{N}$ treatments and three sampling dates from the 42th day after culture to final harvest indicates the importance of cell size in determining tuber dry-matter accumulation. Also, the duration of tuber growth was shorter in the low nitrate-ammonia treatment (Fig. 2). About

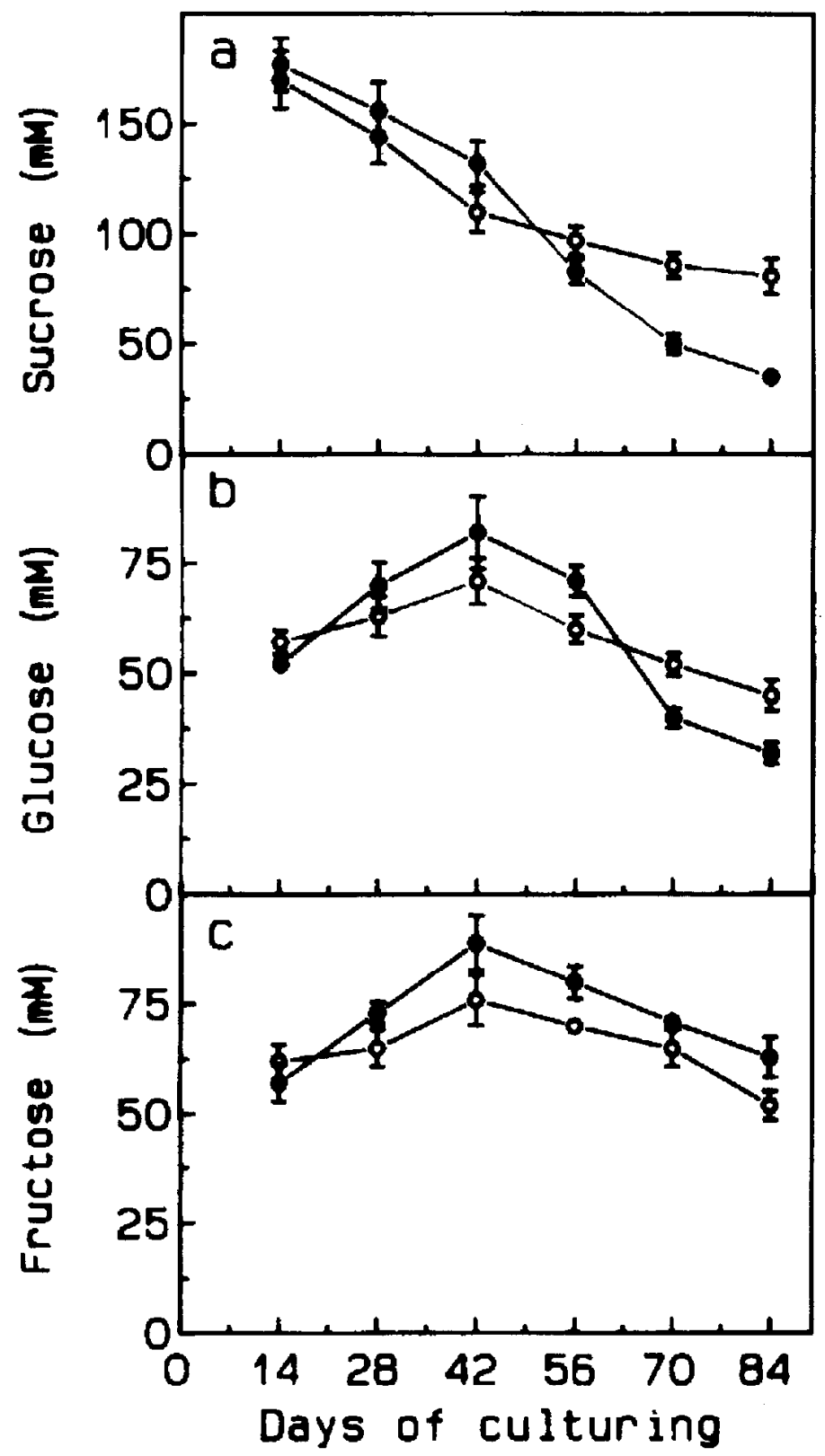

Fig. 3. Changes in concentrations of sucrose (a), glucose (b), and fructose (c) in medium containing high $(5: 1)(0)$ or low $(2: 1)(O)$ nitrate-ammonia during potato tuber development. Vertical bars denote $\pm \mathrm{SE}$. 
$95 \%$ of the final dry weight was accumulated by day 56 and 70 of culture for the low and high nitrate-ammonia treatments, respectively. Similar results have been reported on other crops under $\mathrm{N}$ stress (Mezzetti et al., 1991).

Sucrose concentration in the medium decreased steadily after the explants were introduced (Fig. 3a). High nitrate-ammonia caused significant changes in sucrose concentrations, relative to low nitrate-ammonia, from day 42 to 84 of culture. Sucrose concentrations measured at day 84 of culture were $15 \%$ and $35 \%$ of the initial values for high and low nitrate-ammonia treatments, respectively. Hisajima and Ito (1983) suggested that sucrose was hydrolyzed by cell wall bond invertase and that the glucose produced was used by the cells. In our study, glucose and fructose concentrations in the medium increased with the concurrent decrease of sucrose concentration during the first 42 days of culture (Fig. $3 \mathrm{~b}$ and c). In the low nitrate-ammonia treatment, the rate of glucose depletion paralleled the rate of sucrose depletion from day 42 to 84 of culture. However, the high nitrate-ammonia treatment accelerated glucose depletion, starting on day 56 (Fig. 3b). A consistent but slower decrease in fructose concentration was recorded for both $\mathrm{N}$ treatments (Fig. 3c).

The difference in the rates of sucrose and monosaccharide depletion between the two media was reflected by the rate of drymatter accumulation. Many researchers suggested that retardation of $\mathrm{C}$ use in vitro was related to the inadequate amount of $\mathrm{C}$ source available in the medium (Hisajima and Ito, 1983; Stafford and Fowler, 1983). However, this was not the case in the present study. Even with the high sucrose uptake induced by the high nitrateammonia treatment, $\approx 15 \%$ of the initial sucrose remained in the

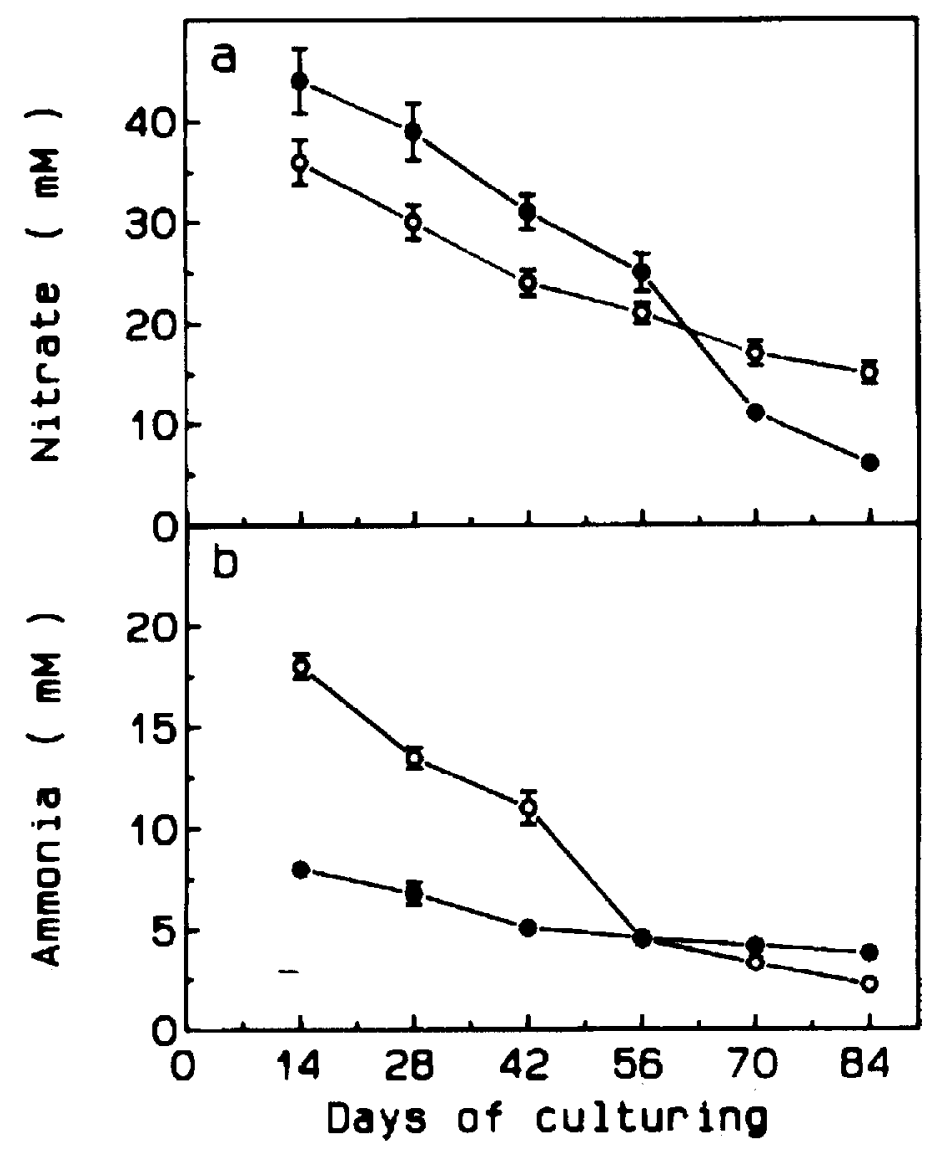

Fig. 4. Changes in concentrations of nitrate (a) and ammonia (b) in medium containing high $(5: 1)(\Theta)$ or low $(2: 1)(O)$ nitrate-ammonia during potato tuber development. Vertical bars denote \pm se. medium after 84 days of culture (Fig. 3a).

The time courses of nitrate and ammonia depletion showed that no significant differences in patterns existed between the two treatments before day 42 (Fig. 4). Thereafter, the nitrate concentration dropped more rapidly in the high nitrate-ammonia treatment (Fig. 4a). Ammonia was depleted more rapidly in the low than in the high nitrate-ammonia treatment up to 56 days of culture (Fig. $4 b$ ). The high nitrate-ammonia medium increased $\mathrm{N}$ use (Fig. $4 \mathrm{a}$ and b). After 84 days of culture, $17 \%$ and $28 \%$ of initial total $\mathrm{N}$ remained in the medium for both treatments. A similar result has been reported with potato cuttings. Lower nitrate : ammonium ratios had a detrimental effect on $\mathrm{N}$ use. (Garner and Blake, 1989).

Uptake and use of nutrients are influenced by the $\mathrm{pH}$ of the medium (Schmitz and Lorz, 1990; Stafford and Fowler, 1983). Major changes in the $\mathrm{pH}$ of the medium during tuber development were observed (Fig. 5). During the first 42 days of culture, $\mathrm{pH}$ decreased from 5.7 to 4.2 for the low and 4.5 for the high nitrateammonia medium, respectively. After day 42, $\mathrm{pH}$ increased up to 5.0 in the high nitrate-ammonia medium but continued to decreased to 3.6 in the low nitrate-ammonia medium by 84 days of culture. Schmitz and Lorz (1990) concluded that when ammonium and nitrate ions are present, the preferential uptake of ammonium

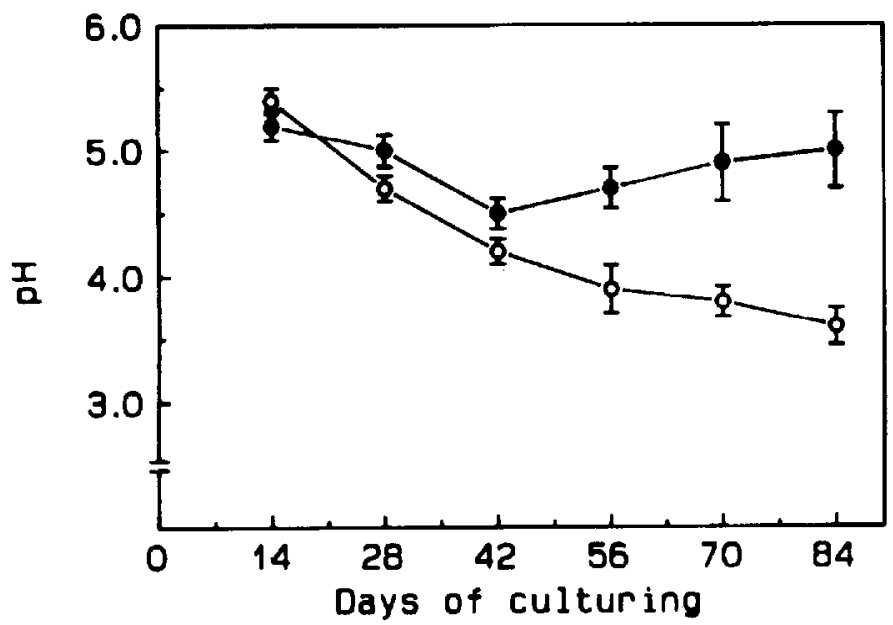

Fig. 5. Time course of $\mathrm{pH}$ changes in medium containing high (5:1) (O) or low (2:1) (O) nitrate-ammonia during potato tuber development. Vertical bars denote \pm SE.

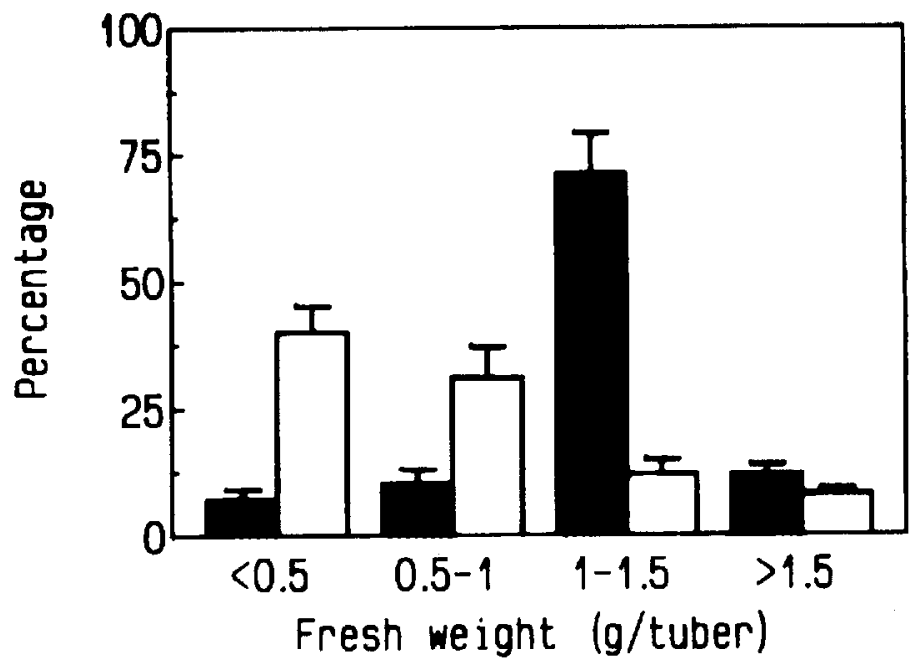

Fig. 6. Weight distribution of potato tubers grown on medium containing high $(5: 1)$ ( ) or low (2:1) (]) nitrate-ammonia. Data were taken 84 days after culture initiation. Vertical bars denote \pm SE. 
ions could cause a drop of $\mathrm{pH}$ in the external medium. It is difficult to provide an explanation for changes in medium $\mathrm{pH}$ based on nitrate and ammonia uptake without knowing the actual flux of other nutrient ions into the tuber. However, it seems that uptake of ammonia from the low nitrate-ammonia medium was associated with the decrease in medium $\mathrm{pH}(r=0.76, P \leq 0.05)$.

Tuber fresh weight ranged from 0.15 to $3.56 \mathrm{~g}$ per tuber, with median values of 1.23 and $0.66 \mathrm{~g}$ for the high and low nitrateammonia treatments, respectively (Fig. 6). In the low nitrate-ammonia treatment, most tubers weighed $<0.5 \mathrm{~g}$, and only $22 \%$ of the tubers was heavier than $1.0 \mathrm{~g}$. The high nitrate : ammonia ratio produced heavier tubers; $\approx 82 \%$ of the tubers had a fresh weight $>1.0 \mathrm{~g}$.

In conclusion, all growth characteristics of potato tubers grown on the two nitrate-ammonia media showed differences from about day 42 of culture. Under low nitrate-ammonia, nutrient uptake, especially of sucrose, was restricted. The growing tuber cells may not develop the maximum potential for enlargement. Increasing the nitrate : ammonia ratio without changing total $\mathrm{N}$ concentration increased $\mathrm{C}$ and $\mathrm{N}$ use, as reflected by the rate of dry-matter accumulation. The nitrate : ammonium ratio in the medium seems to be important in determining $\mathrm{C}$ use, tuber cell size, and tuber weight.

\section{Literature Cited}

Boering Mannheim Biochemical Co. 1989. Methods of biochemical and food analysis. Boering Mannheim Biochemical Co., Mannheim, Germany.

Davis, J.M., W.H. Loescher, M.W. Hammond, and R.E. Thornton. 1989. Response of potatoes to nitrogen form and to change in nitrogen form at tuber initiation. J. Amer. Soc. Hort. Sci. 111:70-72.

Duncan, D.A. and E.E. Ewing. 1984. Initial anatomical changes associated with tuber formation on single-node potato (Solanum tuberosum L.) cutting. Ann. Bot. 53:607-610.

Garner N. and J. Blake. 1989. The induction and development of potato microtubers in vitro on media free of growth regulation substances. Ann. Bot. 63:663-674.

Hisajima, S. and T. Ito. 1983. Activity and cellular distribution of disaccharide in cultured cell of Japanese morning glory. Agr. Biol. Chem. 47:107-109.
Koda, T. and Y. Okazawa. 1983. Characteristic changes on the levels of endogenous plant hormones in relation to the onset of potato tuberization. Jpn. J. Crop Sci. 52:592-597.

Koda, Y. and Y. Okazawa. 1988. Detection of potato tuber inducing activity in potato leaves and old tubers. Plant Cell Physiol. 29:969-974.

Lin, C.H. and L.R. Chang. 1981. Studies on the gall formation of Zizania latifolia Turez. I. Anatomical approach. Proc. Natl. Sci. Council. B. Rep. of China 5:293-296.

Mezzetti, B., L.S. Conte, and P. Rosati. 1991. Actinidia deliciosa in vitro. II. Growth and exogenous carbohydrate utilization by explants. Plant Cell Tissue Organ Cult. 26:153-160.

Murashige, T. and F. Skoog. 1962. A revised medium for rapid growth and bioassay with tobacco tissue culture. Physiol. Plant. 15:473-494.

Peterson, R.C., W.G. Baker, and M.J. Howarth. 1985. Development and structure of tubers, p. 124-152. In: P.H. Li (ed.). Potato physiology. Academic Press, London.

Reeve, R.M., H. Timm, and M.L. Weaver. 1973. Parenchyma cell growth in potato. Amer. Potato J. 50:71-79.

Schmitz, U. and H. Lorz. 1990. Nutrient uptake in suspension cultures of Grammineae. II. Suspension cultures of rice (Oryza sativa L.). Plant Sci. 66:95-111.

Stafford, A. and M. Fowler. 1983. Effect of carbon and nitrogen growth limitation upon nutrient uptake and metabolism in batch cultures of Catharanthus roseus (L.) G. Don. Plant Cell Tissue Organ Cult. 2:239-251.

Sung, F.J.M. and J.J. Chen. 1990. Cotyledon cells and seed growth relationships in CO,-enriched peanut. Peanut Sci. 17:46.

Vreugdenhil, D. and C. Struik. 1989. An integrated view of the hormonal regulation of tuber formation in potato (Solanum tuberosum). Physiol. Plant. 75:525-531.

Wang, P.J. and C.Y. Hu. 1982. In vitro mass tuberization and virus free seed potato production in Taiwan. Amer. Potato J. 59:33-39.

Wiersema, S.G., R. Labello, P. Tovar, and J.H. Dodds. 1987. Rapid seed multiplication by planting into bed microtuber and in vitro plant. Potato Res. 30:117-120.

Ziv, M. 1986. In vitro hardening and acclimation of tissue culture plants, p. 187-196. In: L.A. Withers and P.G. Alderson (eds.). Plant tissue culture and its agriculture application. Butterworths, London. 